\title{
Centrifuge tests to evaluate the effect of depth of water table on seismic response of shallow foundations on silty sands
}

\author{
Amin Borghei ${ }^{1}$, Majid Ghayoomi ${ }^{2, *}$, and Matthew Turner $^{3}$ \\ ${ }^{1}$ Senior Staff Engineer, Geo-Logic Associates, Inc., 3150 Bristol Street, Suite 210, Costa Mesa, California, the United States \\ ${ }^{2}$ Associate Professor, University of New Hampshire, Department of Civil and Environmental Engineering, Kingsbury Hall, W175, \\ Academic Way, Durham, New Hampshire, the United States \\ ${ }^{3}$ Graduate Research Assistant, University of New Hampshire, Department of Civil and Environmental Engineering, Kingsbury Hall, \\ W175, Academic Way, Durham, New Hampshire, the United States
}

\begin{abstract}
A set of dynamic centrifuge experiments were performed to assess the effect of the depth of the groundwater table on the seismic site response of silty sand. Silty sand was prepared in a laminar container. The testing program consists of experiments on dry as well as saturated soils and a test, which the groundwater table was below the soil surface. The specimens were spun in a centrifuge, then they were excited with a suite of seismic motions. Results show that 1) while the for peak ground acceleration amplification factor of the saturated soil was smaller than those for the dry soil, the Arias intensity amplification factor of the saturated soil was larger than those for dry soil. 2) as the depth of the groundwater table increased, peak ground amplification factor and short-period amplification factors increased, the mid-period amplification factors decreased. 3) the depth of the groundwater table influences the frequency content of the free field motion. 4) the unsaturated soil behaved stiffer than dry and saturated soils.
\end{abstract}

\section{Introduction}

The groundwater table separates saturated soils from the unsaturated soils. Previous studies has shown that the dynamic properties of unsaturated soils are different from those of saturated and dry soils [1-7]. Furthermore, it has been observed that seismic site response [8-11], seismically-induced soil settlement $[12,13]$, foundation response in [14-16] unsaturated soils diverge from those for dry and saturated soils. Therefore, the depth of the groundwater table may influence the seismic response of geotechnical systems surrounded by unsturated soils.

Centrifuge modeling is a powerful tool to investigate the seismic responses of complex geotechnical systems [17-20]. This paper presents the results of a set of dynamic centrifuge experiments to evaluate the effect of depth of the groundwater level on the seismic site response of unsaturated silty sand. In this research, silty sand was prepared in a laminar container to reduce undesirable boundary effects on the seismic behavior of the system. Then, a physical model, representing a surface foundation with a width of about $3.5 \mathrm{~m}$, was placed on the soil surface. The experimental program consists of tests on dry as well as saturated soil and a test, where the water table was lowered below the soil surface. The specimens were spun in a geotechnical centrifuge to reach 50-g centripetal acceleration at the soil surface; then they were excited by a suite of realistic earthquake motions. Borghei et al. [16] discussed the effect of the depth of the groundwater table on the seismic settlement of the soil in the free field and below the physical model; while in this study, the centrifuge experiments were analyzed in terms of amplification of seismic motions, the mean period of the free field motion, and the strain-dependent natural frequency of the soils. This study focuses on silty material with higher water retention caoacities than clean sands.

\section{Experimental programs}

\subsection{Geotechnical centrifuge and soil material}

The dynamic centrifuge experiments in this research were performed in the geotechnical centrifuge facility at the University of New Hampshire. The radius of the centrifuge is about 1 meter, and it has a capacity of about 5 g-ton. The centrifuge is equipped with an in-flight shake table. Ghayoomi and Wadsworth [21] provided a detail description of the centrifuge.

The soil material in the research was made by mixing Ottawa sand with 5 percent by weight fine silica silt. The Ottawa sand was produced by US Silica Company under the commercial name of F-75 Unground Silica sand, Plant Ottawa, Illinois, and the fine silica silt was made by Sheffield Pottery Company under the commercial name of Ground Silica, Sil-co-Sil 52. The silty sand was classified was sand with silty (SM) according to USCS classification. Fig. 1(a) shows the grain size distributions of the soils. The tensiometer test was performed to

Corresponding author: majid.ghayoomi@unh.edu 
measure the Soil Water Retention Curves (SWRCs) of the soils, as shown in Fig. 1(b). According to the figure, the air entry value of the silty sand is about $2.5 \mathrm{kPa}$, and the degree of saturation of the soil reached to its residual value when the matric suction was increased to about 12 $\mathrm{kPa}$. Furthermore, the hydraulic conductivity of the soil was measured at about $1.3 \times 10^{-3} \mathrm{~cm} / \mathrm{s}$, by performing a constant head test.

\subsection{Design of the physical model, test layout, and specimen preparation}

Fig. 2(a) shows a photograph of the physical model, called the Steel Foundation Model (SFM). According to the figure, a plastic sheet was attached to the top of the foundation to install vertical accelerometers on the foundation to capture the rocking of the physical model. The mass of SFM is about $489.4 \mathrm{~g}$. The bearing pressure of the foundation at 50-g centripetal acceleration is about $49.9 \mathrm{kPa}$.

Fig. 2(b) shows the schematic test layout and instrumentation of the centrifuge experiment. In this research, sensors such as accelerometers, pore pressure sensors, dielectric sensors and Linear Variable Differential Transformers (LVDTs) were used to measure time histories such as acceleration, pore water pressure, volumetric water content, displacement. The dry compaction technique was used to prepare the soil in the laminar container. A hammer was designed for this purpose. The weight of the hammer and the drop height were calibrated to deposit the soil with the target dry density. The dry density of the soil specimens in this research was about $1669 \mathrm{~kg} / \mathrm{m}^{3}$.

\subsection{Description of the centrifuge experiments}

Table 1 describes the centrifuge experiments performed in this research. The soil specimens in tests SLT_WL.0 and SLT_WL.1 were saturated with water by connecting the drainage valves, located in the bottom of the laminar container, to a tank of de-aired water. Water was allowed to go to the specimen until it passed a few millimeters about the soil surface. Then, the tank was detached from the laminar container.

The capillary rise method was used to lower the depth of the groundwater table during the centrifugation to the target value. The pore pressure sensors were used to monitor the depth of the groundwater table, during the centrifugation. The electronic drainage values of the laminar container were opened and closed promptly to drain some amount of water. Then, the depth of the groundwater table was monitored. The procedure was repeated, until the depth of the groundwater reached the target value. The drained water was collected in the tanks secured below the in-flight shake table to maintain the balance between the mass of the specimen and weights placed in the counterbalance side of the centrifuge. Mirshekari et al. [22, 23] conducted a set of centrifuge experiments where they showed that when the capillary rise method is used to lower the depth of the groundwater table, the soil approximately follows the dry path of its SWRC.

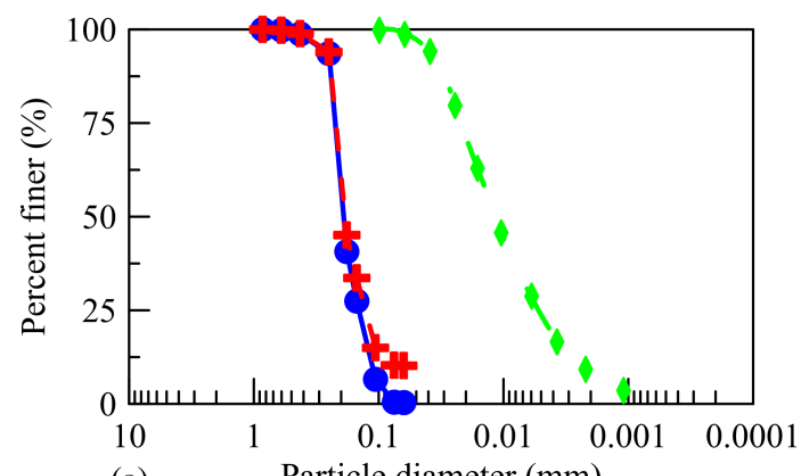

(a) Particle diameter (mm)

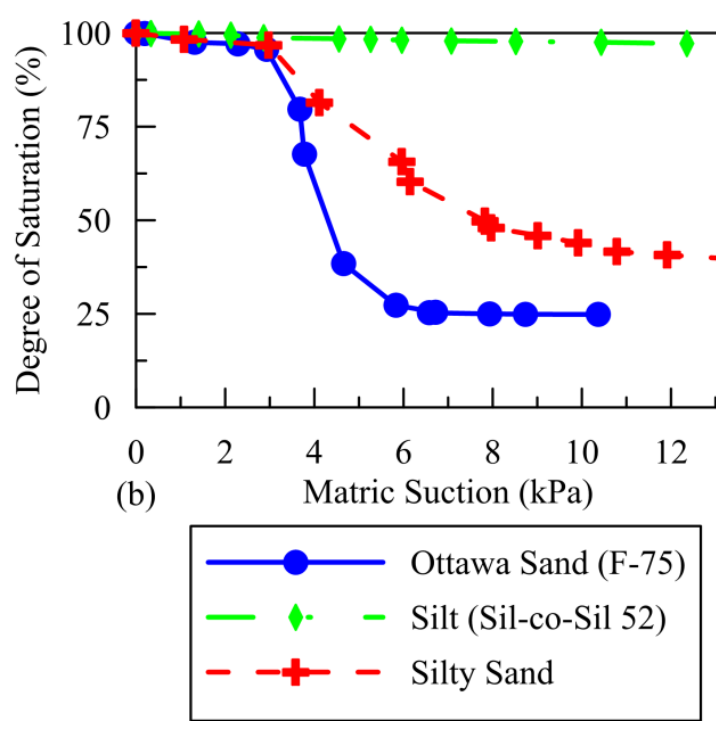

Fig. 1 (a) grain size distributions and (b) soil water retention curves of the soil, used in this research.

Table 1. description of experiments performed in this research.

\begin{tabular}{|c|c|c|}
\hline Test ID & $\boldsymbol{D}_{w, 0}(\mathbf{m})$ & Description \\
\hline SLT_DRY & N/A & Dry soil layer \\
\hline SLT_WL.0 & -0.1 & $\begin{array}{c}\text { Having a groundwater table at } \\
\text { the soil surface }\end{array}$ \\
\hline SLT_WL.1 & 7.1 & $\begin{array}{c}\text { Having a groundwater table } \\
\text { below the soil surface }\end{array}$ \\
\hline $\begin{array}{l}D_{w, 0}: \text { The depth of the pore fluid (in the prototype scale) before } \\
\text { the specimen was excited with the suite of seismic motions. A } \\
\text { positive number means that the groundwater table is below the } \\
\text { soil surface. }\end{array}$ \\
\hline \multicolumn{3}{|c}{} \\
\hline
\end{tabular}

\subsection{Ground motions}

Five historical ground motions, which cover a wide range of ground motion characteristics, were selected for this research. Table 2 describes the seismic motions and the order, which the motions were applied to the specimens. The motions were used to investigate the effect of ground motion characteristics on the seismic site response and kinematic interaction of the 
unsaturated silty sand. The Peak Ground Acceleration (PGA) of the motions was scaled to about $0.1 \mathrm{~g}$. The procedure, developed by Mason et al. [24], was used to calibrate the in-flight shake table of the centrifuge for the motions.

Table 2. Description of the set of the seismic motion, and order in which the specimens were excited with the motions.

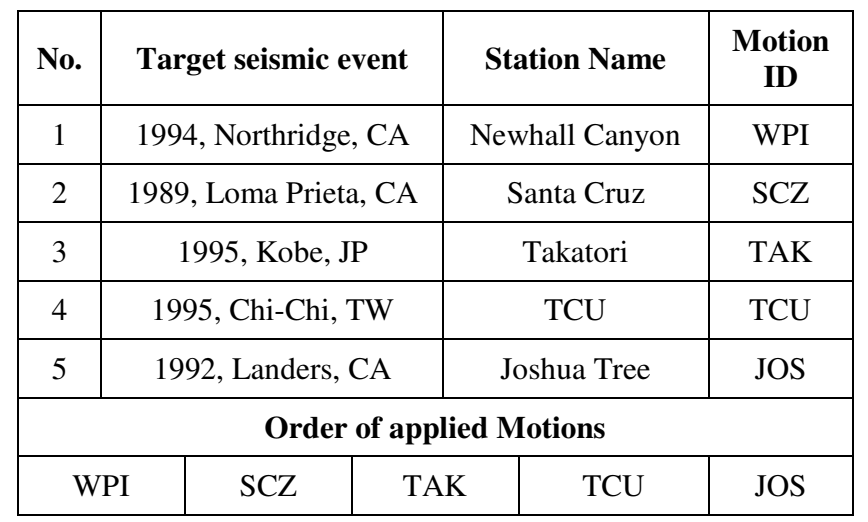

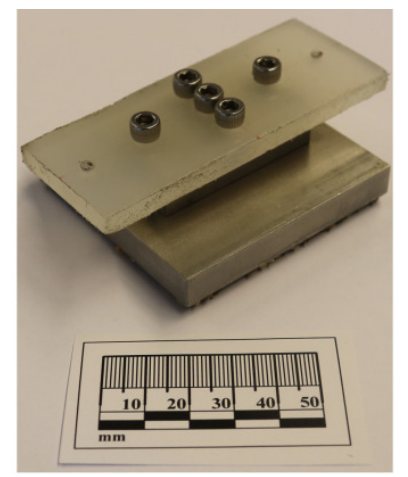

(a)

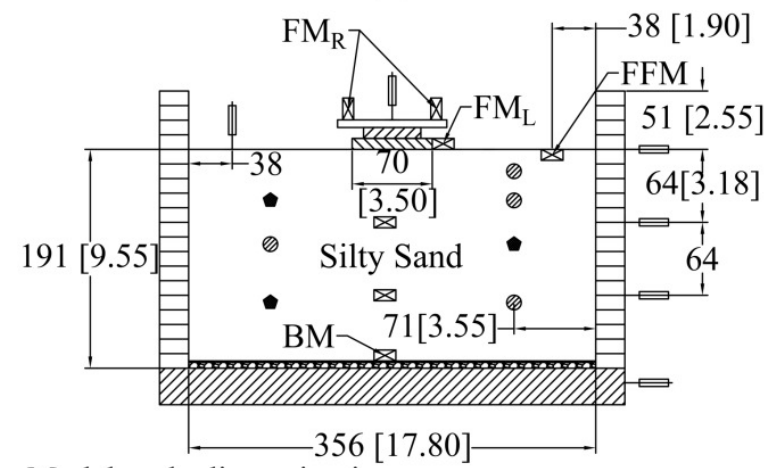

Model scale dimension in $\mathrm{mm}$

[Prototype scale dimension in $\mathrm{m}$ ]

$\bowtie$ Accelerometers Pore Pressure Sensor

$\longmapsto$ LVDT

- Dielectric Sensor

(b)

Fig. 2. (a) a photograph of the Steel Foundation Model (SFM); (b) test layout of the centrifuge experiment in this research.

Fig. 3 shows the ground motion parameters of the base motions achieved in the dry and saturated tests. In this research, the PGA was calculated as the maximum absolute value of the acceleration time histories. The Arias and the Housner intensities and the mean period of motions were calculated as described in [25] and [26]. and [27], respectively. The figure demonstrates that these ground motions covered a wide range of ground motions characteristics. Furthermore, the in-flight shake table could apply approximately identical motions in the two experiments.

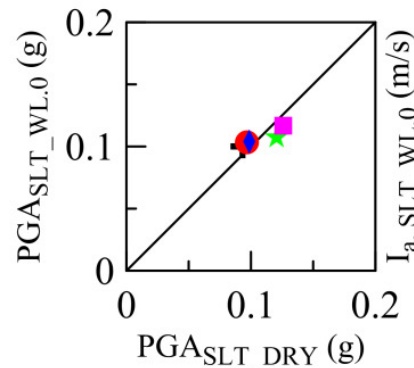

(a)

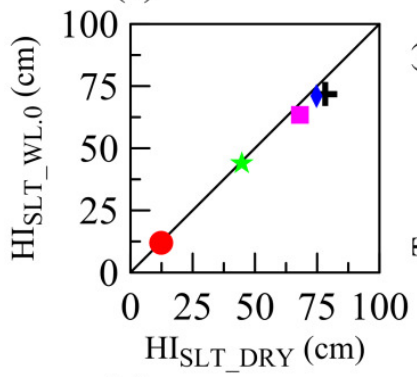

(c)

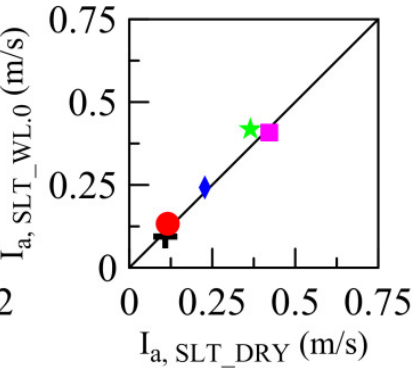

(b)

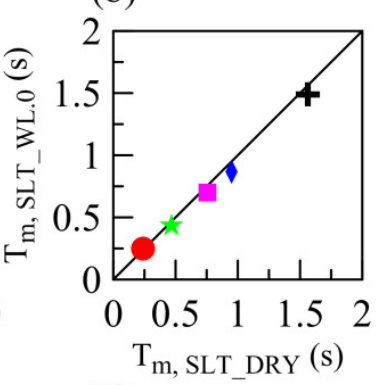

(d)

\section{WPI $\bullet \mathrm{SCZ} \bullet \mathrm{TAK} \star \mathrm{TCU} \backsim \mathrm{JOS}$}

Fig. 3. Ground motion parameters of base motions in the dry and saturated silty sand: (a) Peak Ground Acceleration; (b) Arias intensity ; (c) Housner intensity ; (d) mean period.

\section{Results and discussions}

The analyses, performed in this paper, required that the motions measured at the soil surface far from the physical model acceptably represent the free-field motion. This condition was checked through a series of control centrifuge experiments. The experiments were discussed in detail in [28]. The results herein are presented in the prototype scale.

\subsection{Ground motion amplification}

In this research, the amplification factor for peak ground acceleration, $F_{P G A}$, was defined as the ratio of the PGA of the FFM to the PGA of the BM. The $F_{P G A}$ values were normalized by them to the one for the dry soil. Fig. 4 shows the variation of the normalized peak ground acceleration, $F_{P G A} / F_{P G A, D r y}$, as a function of the normalized the normalized depth of the groundwater table, $D_{W} / b$; where $D_{W}$ and $b$ stand for the depth of the groundwater table and the half-width of the foundation.

The figure shows that the $F_{P G A}$ values for the saturated soil was lower than the values for the dry soil. The generation and dissipation of the pore water pressure could be the main reason for this phenomenon. Also, the 
figure indicates that as the depth of the groundwater table increased, the $F_{P G A}$ values were generally increased, except in WPI motion.

The amplification factor for Arias intensity, $F_{I_{a}}$, was computed by diving the Arias intensity of the FFM to the one for the BM. Fig. 5 shows the variation of the normalized Arias intensity amplification factor, $F_{I_{a}} / F_{I_{a, D R Y}}$, as a function of the normalized depth of the groundwater table. By comparing Fig. 4 and Fig. 5, it can be seen that while the $F_{P G A}$ values for the saturated soil were smaller than the values for the dry soil, the $F_{I_{a}}$ values for the saturated soil were some times larger. Furthermore, as the depth of the groundwater table increased, while the $F_{I_{a}}$ values increased for some motions, they decreased for the other motions.

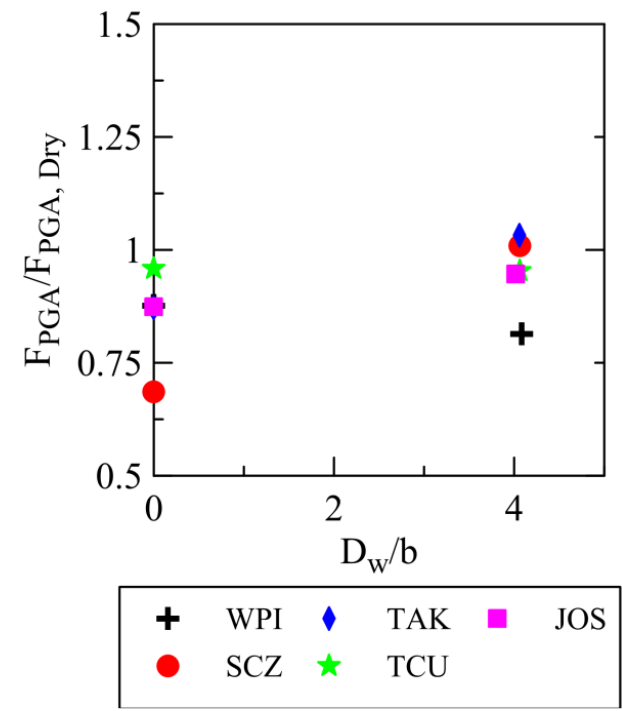

Fig. 4. Variation of the normalized amplification factors of PGA as a function of the normalized depth of the groundwater table, when the silty sand specimen in different experiments were excited with the suite of seismic motions.

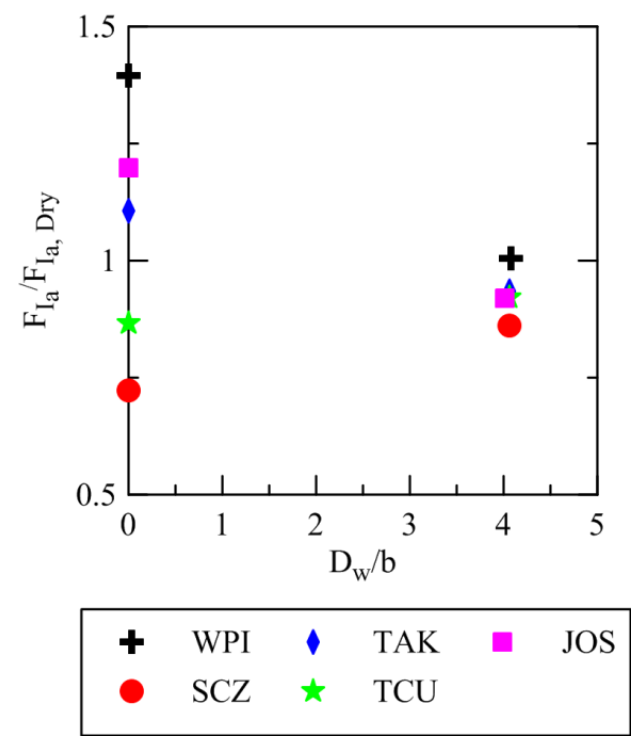

Fig. 5. Variation of the normalized amplification factors of Arias intensity as a function of the normalized depth of the groundwater table, when the silty sand specimen in different experiments were excited with the suite of the seismic motions.
Short-period amplification factor, $F_{a}$, and mid-period amplification factor, $F_{v}$, were calculated in period ranges such as 0.1-0.5 s and 0.4-2 s, respectively, to investigate the frequency-dependent amplification of seismic motions. The amplification factors were computed according to the method described in [29].

Fig. 6 and Fig. 7 show the variations of the normalized short-period amplification factor, $F_{a} / F_{a, \text { Dry }}$, and the normalized mid-period amplification factor, $F_{v} / F_{v, \text { Dry }}$, as a function of the normalized depth of the groundwater table. According to the figures, while the short-period amplification factors of the saturated soil were smaller than those for the dry soil, the mid-period amplification factors were larger than those for the dry soil. Furthermore, as the depth of the groundwater table increased, while the short-period amplification factor increased, the mid-period amplification factor decreased. This observation indicates that the presence of the groundwater table has different effects on the amplification of the ground motions in various frequencies.

\subsection{Mean period of free field motion}

Fig. 8 shows the variations of the normalized mean period of the free field motions, $T_{m} / T_{m, \text { Dry }}$, as a function of the normalized depth of the groundwater table. According to the figure, the $T_{m}$ values of the saturated soil were larger than those for the dry soil; furthermore, as the depth of the groundwater table increased, the $T_{m}$ values roughly decreased. This observation indicates that the depth of the groundwater table can influence the frequency content of the ground motions.

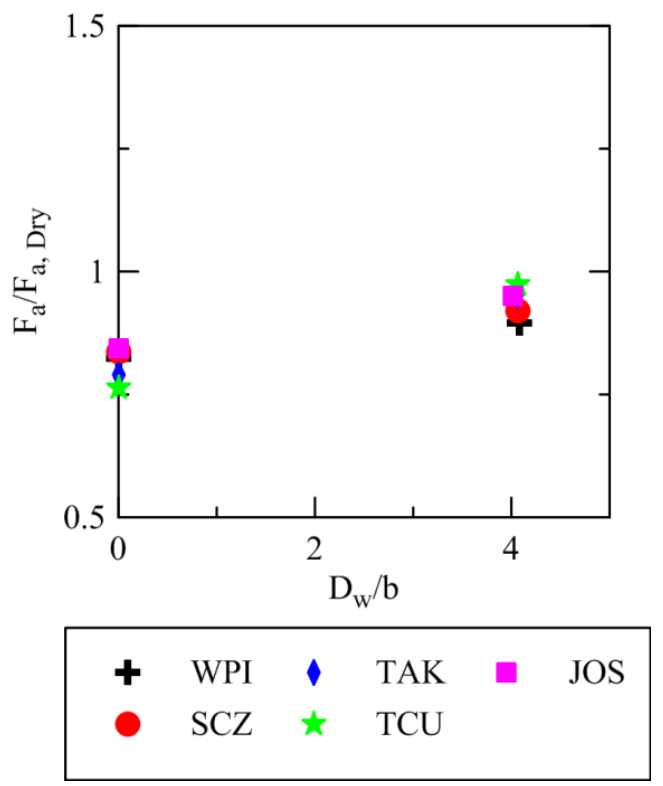

Fig. 6. Variation of the normalized short-period amplification factors as a function of the normalized depth of the groundwater table, when the silty sand specimens in different experiments were excited with the suite of the seismic motions. 


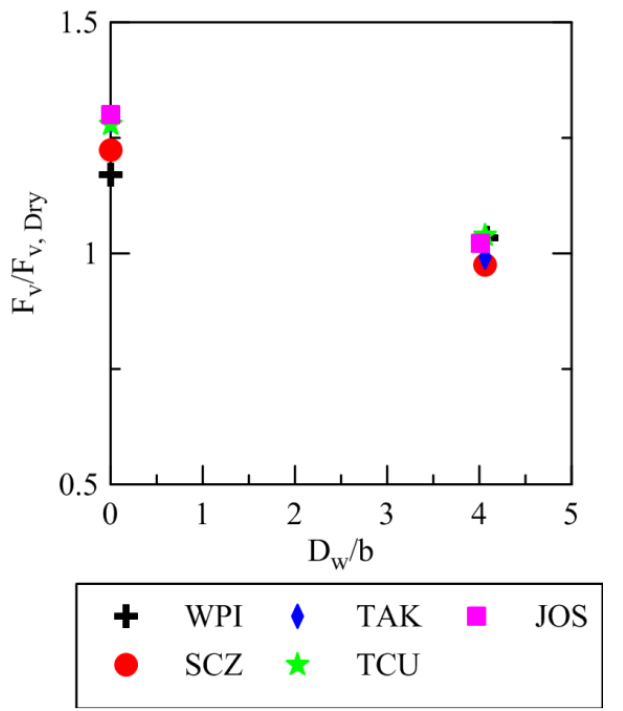

Fig. 7. Variation of the normalized mid-period amplification factors as a function of the normalized depth of the groundwater table, when the silty sand specimens in different experiments were excited with the suite of the seismic motions.

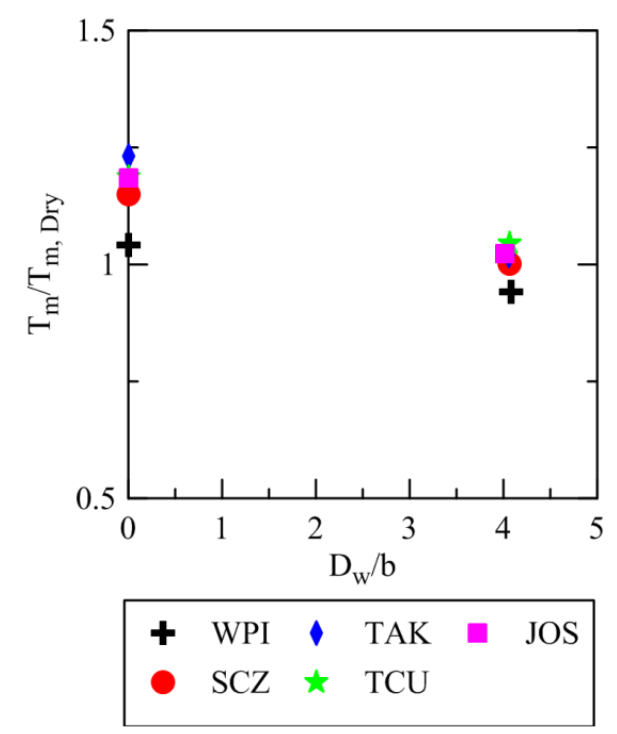

Fig. 8. Variation of the mean period of free field motions as a function of the normalized depth of the groundwater table, when the silty sand specimens in different experiments were excited with the suite of the seismic motions.

\subsection{The strain-dependent natural frequency of the soils}

The $f_{s}$ values for the silty-sand in the dry and saturated conditions were computed as $6.0 \mathrm{~Hz}$, and $4.9 \mathrm{~Hz}$, respectively, using the closed-form solutions developed by Idriss and Seed [30]. As expected, the $f_{s}$ value of the soil in dry condition was larger than that in the saturated condition due to larger effective stress of the dry soil compared to the saturated soil. In this study, the straindependent natural frequency of the soil, $\tilde{f}_{s}$, was computed by estimating transfer functions between the base motion and the free field motion. The $\tilde{f}_{s}$ values were selected as frequencies corresping to the peak in the transfer function. The results indicate that the $\tilde{f}_{S}$ values were smaller than the $\mathrm{f}_{\mathrm{s}}$ values, due to inducedshear strain in the soils, when the soil specimens were excited with different seismic motions.

Fig. 9 shows the variations of the normalized straindependent natural frequency, $\tilde{f}_{s} / \tilde{f}_{s, \text { Dry }}$, as a function of the normalized depth of the groundwater table. According to the figure, the $\tilde{f}_{s}$ values of the saturated soil were generally smaller than those for the dry soil. The lower effective stress in the saturated soil compared to the dry soil could be the main reason for this observation. Furthermore, when the depth of the groundwater table was increased, the $\tilde{f}_{s}$ values incresee, and they even become larger than values for the dry soil. This observation indicated that the soil layer having the groundwater table below the soil surface behaved stiffer than even dry soil.

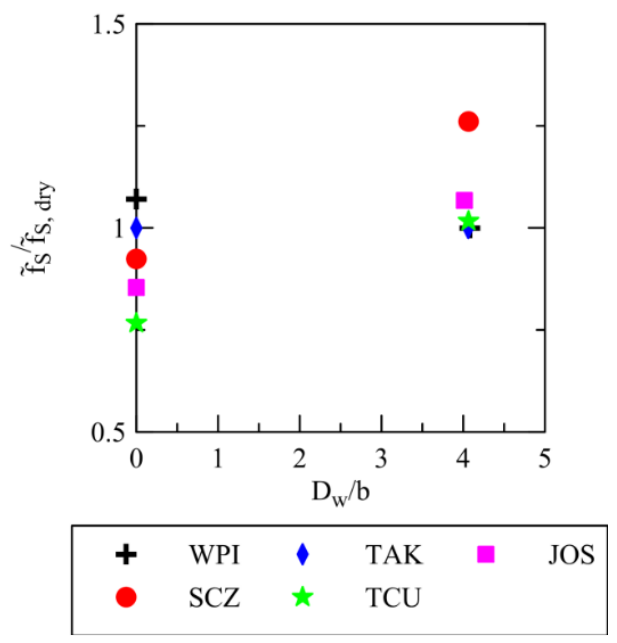

Fig. 9. Variation of the normalized strain-dependent natural frequency of the sandy soils as a function of the normalized depth of the groundwater table, when the silty sand specimens in different experiments were excited the suite of the seismic motions.

\section{Conclusions}

In this research, a set of dynamic centrifuge experiments was conducted to investigate the effect of the depth of the groundwater table on the seismic site response of unsaturated silty sand. The results of the experiments can be concluded as follows: 1) While the PGA and shortperiod amplification factors of the saturated soil were smaller those for the dry soil, the mid-period amplification factors of the saturated soil were larger than those for the dry soil; 2) As the depth of the groundwater table was increased, while the PGA and short-period amplification factors roughly increased the mid-period amplification factors decreased; 3) the depth of the groundwater table influences the frequency content of the free field motion; 4) the strain-depenent natural frequencies of the unsaturated soils were larger than saturated and dry soil. These observations indicate that unsaturated soil behaved stiffer than dry and saturated soils. These trends are vsisible for silty sand material with relatively high water retention. 


\section{References}

1. S. Wu, D. Gray, J. Richart J. Geotech. Eng. 110(9):1188-1203 (1984)

2. X. Qian, D. Gray, R. Woods Geotech Test J 14(3):266-275 (1991)

3. C. Mancuso, R. Vassallo, A. d'Onofrio Can Geotech J 39(1):22-31 (2002)

4. C. Mendoza, J. Colmenares, V. Merchan Proc., Int. Symp. on Advanced Experimental Unsaturated Soil Mechanics. (2005)

5. R. Vassallo, C. Mancuso, F. Vinale Can geotec j 44(4):447-462 (2007)

6. M. Biglari, M. Jafari, A. Shafiee, C. Mancuso , A. d'Onofrio Geotech Test J 34(5):525-536 (2011)

7. L. Hoyos, E. Suescún-Florez, A. Puppala Eng. Geol. 188(1):10-28 (2015)

8. J. Yang, T. Sato Bull. Seismol. Soc. Am. 90(5):1313-1317( 2000)

9. J. Yang J. Geotech. Geoenviron. Eng. 132(4):526531( 2006)

10. F. D'Onza, A. D'Onofrio, C. Mancuso 1st European Conference on Unsaturated Soils. (2008)

11. M. Mirshekari, M. Ghayoomi Soil Dyn. Earthquake Eng. 94, 254-265(2017)

12. M. Ghayoomi, J. McCartney, H. Ko. Geotech Test J 34(4):321-331 (2011)

13. M. Ghayoomi, J. McCartney, H. Ko J. Geotech. Geoenviron. Eng. 139 (3):367-376(2013)

14. M. Ghayoomi, S. Ghadirianniari, A. Khosravi, M. Mirshekari Soil Dyn. Earthquake Eng. 112(1):162173 (2018)

15. L. Lalicata, A. Desideri, F. Casini, L. Thorel Can Geotech J 56(1):( 2018)

16. A. Borghei, M. Ghayoomi, M. Turner Geo-congress 2020

17. B. Ghosh, S. Madabhushi Nucl. Eng. Des. 237(8):887-896 (2007)

18. A. Borghei, M. Ghayoomi International Journal of Physical Modelling in Geotechnics (2019)

19. A. Borghei, M. Ghayoomi 7th International Conference on Earthquake Geotechnical Engineering (2019)

20. A. Borghei, M. Ghayoomi. Soil Dynamics and Earthquake Engineering 125(1):1-11 ( 2019)

21. M. Ghayoomi, S. Wadsworth 8th International Conference on Physical Modelling in Geotechnics (2014)

22. M. Mirshekari, M. Ghayoomi, A. Borghei. Geotech Test J 41(6): ( 2018)

23. M. Mirshekari, M. Ghayoomi, A. Borghei 9th International Conference in Physical Modeling in Geotechnics (ICPMG) (2018)

24. H. Mason, B. Kutter, J. Bray, D. Wilson, B. Choy 7th International Conference on Physical Modeling in Geotechnics (2010)
25. A. Arias A measure of earthquake intensity. :Cambridge, MA.The Mass Inst. Tech. Press. (1970)

26. G. Housner Behavior of structures during earthquakes. J. of the Eng. Mech. Div. 85 (4):109130 (1959)

27. E. Rathje, N. Abrahamson, J. Bray J Geotech Geoenviron Eng 124 (2):150-159 (1998)

28. A. Borghei Seismic Response of Soil-Foundation Systems on Unsaturated Ground, Ph.D. Dissertation, University of New Hampshire (2019)

29. R. Borcherdt Earthquake Spectra 10(4): 617653(1994)

30. I. Idriss, H. Seed J Soil Mech Found Div 94(4):1003-1031(1968) 